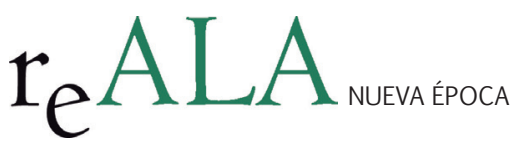

REALA, n Extraordinario, enero 2015 ISSN: 1989-8975

DOI: http://dx.doi.org/10.24965/reala.voiExtra.10225

\title{
La aplicación autonómica de la Ley de Racionalización y Sostenibilidad de la Administración Local'
}

\author{
Alfredo Galán Galán \\ Profesor Titular de Derecho Administrativo (Acreditado para Catedrático). Universidad de Barcelona \\ alfredogalan@ub.edu
}

\section{Resumen}

La aplicación de la Ley de Racionalización y Sostenibilidad de la Administración local debe superar muchos e importantes obstáculos: la generación por la ley de dudas interpretativas, la falta de previsión en ella de un adecuado régimen transitorio, su aplicación territorial asimétrica o diferenciada y el rechazo generalizado que su aprobación ha causado. El presente estudio, tras examinar estos motivos, entra a analizar en profundidad la aplicación que de esa ley están realizando las comunidades autónomas.

Palabras clave

Gobiernos locales; autonomía local; régimen local; reforma local.

\section{Autonomic Application of the Rationalization and Sustainability of Local Administration Act}

Abstract

The put in practice of the Law 27/2013, of 30 December, on the Rationalization and Sustainability of Local Government, must beat various and important obstacles: doubts on its interpretation, the lack of an adequate transitional regime, asymmetric measures for different territories and the commonly known rejection to its pass. In this article we will study deeply the way the autonomous communities are putting in practice this Law.

Key words

Local governments, local self-government, local model, local reform.

1 Este trabajo se enmarca en el proyecto de investigación DER2012-39216-C02-01, que lleva por título “Público y privado en la reordenación de las competencias locales”, financiado por el Ministerio de Economía y Competitividad y del que es investigador principal Alfredo Galán Galán. 
1. LAS DIFICULTADES PARA LA APLICACIÓN DE LA LEY. 2. LA GENERACIÓN POR LA LEY DE IMPORTANTES DUDAS INTERPRETATIVAS. 3. LA FALTA DE PREVISIÓN EN LA LEY DE UN ADECUADO RÉGIMEN TRANSITORIO. 4. LA APLICACIÓN TERRITORIAL DIFERENCIADA DE LA LEY. 5. EL RECHAZO GENERALIZADO DE LA LEY. 6. LA TORTUOSA APLICACIÓN DE LA LEY POR LAS COMUNIDADES AUTÓNOMAS.

\section{LAS DIFICULTADES PARA LA APLICACIÓN DE LA LEY}

La aplicación de la Ley 27/2013, de 27 de diciembre, de Racionalización y Sostenibilidad de la Administración Local (en adelante, LRSAL), esto es, la transformación de la realidad local atendiendo a este mandato legislativo, debe superar no pocos obstáculos. Este problema fue diagnosticado ya durante la larga y atormentada tramitación de la disposición legal y ahora, pasado un año desde su entrada en vigor, su existencia es innegable.

Las principales razones que, en nuestra opinión, explican esta dificultad aplicativa son las siguientes: la generación por la ley de importantes dudas interpretativas, la falta de previsión en ella de un adecuado régimen transitorio, su aplicación territorial diferenciada y el rechazo generalizado que ha causado.

\section{LA GENERACIÓN POR LA LEY DE IMPORTANTES DUDAS INTERPRETATIVAS}

Pocas veces una ley ha generado tantas dudas en lo sujetos llamados a aplicarla. Si una de las funciones del Derecho es aportar certidumbre a las relaciones sociales, reduciendo así el alcance de la inseguridad, podemos concluir que la LRSAL no la cumple satisfactoriamente. En efecto, entre las finalidades perseguidas por su autor, como ya se deduce del título de la ley y expresamente se recoge en su preámbulo, están la "clarificación" (del sistema de competencias locales) y la "racionalización” (de la estructura organizativa de la Administración local). Pues bien, podemos afirmar sin lugar a dudas que tales objetivos no se han alcanzado. Antes al contrario, su entrada en vigor ha incrementado en el nivel local de gobierno tanto las incertidumbres como la dosis de irracionalidad que, como veremos más adelante, roza el verdadero caos en lo referente a su desarrollo aplicativo por las comunidades autónomas y por las entidades locales.

En la generación de estas dudas por la ley, importantes tanto en número como en relevancia, han confluido varios factores. Los principales son lo siguientes:

a) El mejorable proceso de elaboración de la ley.

Anunciada la decisión política de tirar adelante esta iniciativa legislativa, empezaron a circular numerosos borradores cuyos contenidos variaban en aspectos medulares ${ }^{2}$. A la desorientación causada se sumó una fuerte oposición de los responsables políticos locales, así como una generalizada crítica de la doctrina científica especializada. Por estos motivos, y quizá por otros añadidos, lo cierto es que el proyecto, a pesar de que su título permaneció inmutable, con el pasar del tiempo y el suceder de las versiones, se fue despojando cada vez más de su carácter "racionalizador" para centrarse en su obsesión de asegurar la "sostenibilidad" financiera.

El análisis comparativo de todos los borradores de texto, si se ha tenido la diligencia y paciencia de irlos guardando, revela, además de sorprendentes contradicciones, una tendencia cada vez más marcada a suavizar el alcance de las medidas contenidas. De este modo, algunos de los contenidos más controvertidos desaparecerán o bien verán debilitada su incidencia. Desde luego, se abandonó pronto la idea de introducir orden en la planta local, especialmente mediante la supresión forzosa de municipios, y se perdonó la vida de las entidades de ámbito territorial inferior al municipio ya existentes; se dulcificó el trato inicialmente previsto para mancomunidades y consorcios; la controvertida noción del coste estándar desapareció dejando en su lugar al más aceptable coste efectivo; y, por terminar, el redimensionamiento del sector público local se trató de alcanzar con una regulación plagada cuanto menos de sombras. El esfuerzo de la reforma se centró, de este modo, en rediseñar parcialmente las relaciones interadministrativas, configurando traslados competenciales, y, claro está, en prever drásticas medidas de aseguramiento de la sostenibilidad financiera de las entidades locales, en clara tensión con su autonomía. Un momento especialmente relevante del proceso de gestación fue el duro impacto que

2 Estas ideas aparecen ya en FONT i LLOVET, Tomás y GALÁN GALÁN, Alfredo, “La reordenación de las competencias municipales: ¿una mutación constitucional?”, en Anuario del Gobierno Local 2013, Fundación Democracia y Gobierno Local - Instituto de Derecho Público, 2014, pp. 21 y 22. 
sobre el texto supuso el Dictamen del Consejo de Estado de 25 de junio de 2013, en la medida en que provocó un cambio sobre aspectos que se habían publicitado como centrales de la reforma en curso.

En realidad, las modificaciones de importancia se introdujeron hasta el último minuto, incursos ya en la tramitación parlamentaria del proyecto de ley. Algunas de ellas fueron dirigidas a diluir algunas medidas, a aplazar su aplicabilidad o, sin más, a excluir su aplicación en algunos territorios.

b) La deficiente técnica normativa empleada.

Con independencia del acierto de las medidas elegidas, desde la perspectiva de la técnica normativa empleada, la ley merece una valoración negativa. De entrada, como ya hemos visto y con carácter general, por la forma en que se llevó el proceso desde su gestación hasta la entrada en vigor de la reforma. Pero también, en concreto, por la manera en que se abordó la regulación de muchas de las novedades introducidas.

Para ilustrar esta afirmación nos puede servir de ejemplo la disposición adicional decimosexta que se adiciona a la Ley $7 / 1985$, de 2 de abril, reguladora de las Bases de Régimen Local (en adelante, LBRL). Como es sabido, dotándole de una naturaleza excepcional, y siempre que se cumplan los requisitos allí establecidos, esta norma traslada del pleno de la corporación a la junta de gobierno local la competencia para la toma de determinadas decisiones, incluida la aprobación del presupuesto de la entidad. Decisiones que tienen como denominador común su relevancia, un claro contenido económico y una estrecha relación con los instrumentos de lucha contra la crisis económica y el aseguramiento de los principios de estabilidad presupuestaria y sostenibilidad financiera ${ }^{3}$. Pues bien, desde el punto de vista de la corrección de la técnica normativa, es discutible el acierto de incluir esta notable peculiaridad al régimen común como una disposición adicional de la ley. Así lo ha destacado el Gobierno de Canarias en su propuesta de resolución del recurso de inconstitucionalidad contra la LRSAL (recogido en el Dictamen 172/2014, de 8 de mayo, del Consejo Consultivo de Canarias). El ejecutivo autonómico, en efecto, considera que la ley es merecedora “de un especial reproche": "En primer lugar, aunque no sea el más importante, por la técnica legislativa empleada al situar el precepto como una disposición adicional. Si se atiende a su rúbrica, referida a la mayoría requerida para la adopción de acuerdos en las corporaciones locales, es evidente que debería formar parte del cuerpo de la normativa básica que regula el régimen local y no figurar como una disposición complementaria de derecho especial, por tratar en realidad de un aspecto nuclear sobre la formación y expresión de la voluntad de la institución".

Pero esta disposición adicional decimosexta nos guarda una sorpresa cuando el estudioso se remonta al momento de su gestación. Partamos del hecho de que esta norma no estaba en el proyecto de ley presentado por el Gobierno, sino que se incorporó durante su tramitación en el Congreso ${ }^{4}$. Pues bien, durante la tramitación parlamentaria, la inclusión de los presupuestos dentro del listado de supuestos en los que la disposición resulta de aplicación fue calificada expresamente por los impulsores de la reforma como un "error". Curiosamente, sin embargo, no hubo finalmente ninguna rectificación. En efecto, en el debate del proyecto de ley en la Comisión de Hacienda y Administraciones Públicas, el Sr. José Alberto Martín-Toledano Suárez, en nombre del Grupo Parlamentario Popular, al tomar la palabra afirmó lo siguiente: "hemos planteado a los letrados de la Mesa unas correcciones técnicas de algunas enmiendas del Grupo Popular. En concreto, en cuanto a la 420, que se refiere a la asunción por la junta de gobierno de determinadas competencias de pleno, teníamos dos borradores y por error se presentó aquel en el que figuraba que la aprobación del presupuesto sería asumida por la junta de gobierno. Mantendríamos las otras competencias, pero no la aprobación del presupuesto" ${ }^{5}$.

c) La complejidad técnica de la regulación y su marcado carácter economicista.

Para ser justos, debe admitirse que parte de las dudas interpretativas que genera la ley pueden derivar del alto grado de complejidad que caracteriza a algunos de sus contenidos. Sirva como ejemplo, entre otros muchos, la referencia que la disposición adicional decimocuarta LRSAL hace al Sistema Europeo de Cuentas para la calificación de los consorcios como administración pública a los efectos de excluirlos de la aplicación de la nueva obligación de adscripción.

3 GALÁN GALÁN, Alfredo y PANADÉS JORDÁ, Pau, “La aprobación de los presupuestos municipales sin participación ciudadana: de la cuestión de confianza a la atribución de la competencia a la junta de gobierno”, en Cuadernos de Derecho Local, n³6, 2014, pp. 47-69.

4 En concreto, se introdujo a través de la Enmienda núm. 420, del Grupo Parlamentario Popular; Boletín Oficial de las Cortes Generales, Congreso de los Diputados, X Legislatura, Serie A: Proyectos de ley, núm. 58-2, 30 de octubre de 2013, p. 293.

5 En Diario de Sesiones del Congreso de los Diputados, Comisiones, X Legislatura, núm. 451, sesión núm. 19, celebrada el miércoles 30 de octubre de 2013, p. 15 . 
Por lo general, la dificultad que encuentra el jurista para la correcta comprensión de estos preceptos deriva de su marcada impronta económica. No hay que olvidar que el proyecto de ley proviene de un ministerio que significativamente reúne la hacienda con las administraciones públicas y, quizá no por casualidad, en cuya denominación aparecen mencionadas por este mismo orden. Aún a riesgo de equivocarnos, nos parece que en la elaboración de bastantes de los pasajes del texto legal, la pluma ha sido empuñada por manos más expertas en economía que en derecho. Lo que, en realidad, no deja de guardar coherencia con la finalidad perseguida: el aseguramiento en el ámbito local de los principios de estabilidad presupuestaria y de sostenibilidad financiera. Porque lo cierto es que el criterio rector de la reforma, tenido en cuenta de un modo casi exclusivo, no es otro que el económico de la eficiencia ${ }^{6}$.

La suma de todos los factores indicados trae como consecuencia la existencia de una gran inseguridad jurídica. Incertidumbre que ha originado reacciones diversas en los propios gobiernos locales. Así, mientras algunos han seguido operando como si no se hubiera aprobado la reforma, otros, en cambio, han tendido a paralizar su actividad en caso de duda, cesando en la prestación de algunos servicios, ante el temor de incumplir la ley e incurrir en responsabilidad. Buscando certezas, algunas entidades locales comenzaron a aprobar sus propias guías de aplicación, ofreciendo pautas interpretativas de la ley y aclaraciones en sus puntos oscuros?

Que estas dudas existen y que es necesario hacerles frente parece fuera de toda duda. Incluso para el propio autor de la reforma. En efecto, sorprendentemente, en un acto de reconocimiento implícito de los problemas generados, el Ministerio de Hacienda y Administraciones Públicas, difundió una "Nota explicativa de la Reforma Local”, de 5 de marzo de 2014, cuya naturaleza y valor jurídico quedan indeterminados. Ejemplo seguido después por algunas comunidades autónomas, como es el caso de Cataluña, quien hizo pública, el 16 de abril de 2014, una "Nota explicativa de la Secretaria de Cooperación y Coordinación de las Administraciones locales sobre la aplicación en Cataluña de determinados aspectos de la Ley 27/2013, de 27 de diciembre, de racionalización y sostenibilidad de la Administración local”. Otras instancias, públicas o privadas, por último, han querido contribuir igualmente a aclarar el significado de la reforma. Así, destacadamente, la Fundación Democracia y Gobierno local aprobó una "Guía práctica sobre la Ley de Racionalización y Sostenibilidad de la Administración Local", de febrero de 2014. Nos encontramos, en definitiva, ante una proliferación de manuales de instrucciones acerca del correcto uso de la ley que, en ocasiones, incurren entre si en contradicciones y que, a pesar de la buena voluntad que los anima, pueden incrementar el desconcierto existente.

\section{LA FALTA DE PREVISIÓN EN LA LEY DE UN ADECUADO RÉGIMEN TRANSITORIO}

Una reforma de tanto calado, de tan alta complejidad y de difícil aplicación por tantas entidades locales habría aconsejado la previsión en la ley de una regulación transitoria adecuada. En nuestra opinión, tal cosa no ha sucedido. Y no ha ocurrido, en realidad, por una doble razón. Por un lado, debido a la falta de un régimen transitorio para la mayor parte del contenido de la ley que, de esta manera, se traduce en su inmediata entrada en vigor. Y, por el otro, por la falta de acierto del régimen transitorio en algunos de los casos concretos en que ha estado previsto, particularmente por su falta de claridad. Sirva de ejemplo el régimen transitorio previsto para las entidades de ámbito territorial inferior al municipio o bien para la asunción por las comunidades autónomas de las competencias relativas a educación, salud, inspección sanitaria y servicios sociales. Y muy especialmente para los consorcios, cuyo régimen jurídico se ha visto nuevamente modificado, en los aspectos relativos a la separación y disolución, por la Ley 15/2014, de 16 de septiembre, de Racionalización del Sector Público, cuyo art. 15 establece un nuevo plazo de adaptación de los estatutos consorciales.

\section{LA APLICACIÓN TERRITORIAL DIFERENCIADA DE LA LEY}

La reforma local nace con una finalidad bien clara: adaptar la normativa básica en materia de régimen local a las exigencias derivadas de los principios de estabilidad presupuestaria y sostenibilidad financiera del nuevo art.

6 Que la reforma local tenga en cuenta el criterio de la eficiencia no solamente es conveniente, sino del todo necesario. Ya lo era antes, pero con mayor intensidad lo es tras la reforma del art. 135 de la Constitución (en adelante, CE) y, con ello, el refuerzo constitucional de los principios de estabilidad presupuestaria y sostenibilidad financiera. La crítica, por lo tanto, no debe buscarse ahí. Sí que debe hacerse, en cambio, por el hecho de que el legislador lo haya tenido en cuenta con un grado de protagonismo tal que, de hecho, no resulta compensado con otros criterios que cuentan con un igual anclaje constitucional, como son los relativos al principio democrático o a la autonomía local. Una reflexión sobre esta crítica puede encontrarse en FONT i LLOVET, Tomás y GALÁN GALÁN, Alfredo, "La reordenación de las competencias municipales: ¿una mutación constitucional?”, ob. cit., pp. 15-18.

7 Sirvan de ejemplo las dos Circulares informativas de la Diputación de Huesca, la primera relativa genéricamente a la LRSAL, de 17 de enero de 2014, y la segunda específicamente al empleo público, de 20 de enero de 2014; el Informe de la Oficina Técnica de Presidencia, Economía y Hacienda del Ayuntamiento de Zaragoza, de 24 de enero de 2014, sobre la evaluación de la afectación de la LRSAL a los servicios prestados por el Ayuntamiento de Zaragoza; la Circular informativa de la Diputación de Valladolid sobre la LRSAL de 23 de enero de 2014 ; y la Instrucción de 20 de junio de 2014 por la que se establece el marco y los criterios generales de aplicación de la LRSAL en el Municipio de Barcelona. 
135 CE. Así aparece expresamente confesado en el párrafo primero del preámbulo de la LRSAL: "La reforma del artículo 135 de la Constitución española, en su nueva redacción dada en 2011, consagra la estabilidad presupuestaria como principio rector que debe presidir las actuaciones de todas las Administraciones Públicas. En desarrollo de este precepto constitucional se aprobó la Ley Orgánica 2/2012, de 27 de abril, de Estabilidad Presupuestaria y Sostenibilidad Financiera, que exige nuevas adaptaciones de la normativa básica en materia de Administración local para la adecuada aplicación de los principios de estabilidad presupuestaria, sostenibilidad financiera o eficiencia en el uso de los recursos públicos locales. Todo ello exige adaptar algunos aspectos de la organización y funcionamiento de la Administración local así como mejorar su control económico-financiero".

La finalidad indicada justifica que la reforma local haya encontrado amparo competencial, al menos en el grueso principal de su contenido, en la alegación por el Estado del art. 149.1.18 CE (disposición final quinta LRSAL). De lo que se trata, por lo tanto, es de modificar la regulación básica existente sobre régimen local con nuevas normas que tienen un igual carácter básico. Y que, por consiguiente, tienden a aplicarse de manera uniforme en la totalidad del territorio estatal. Desde esta perspectiva, no falta razón a la crítica que tacha la reforma de recentralizadora en el ámbito local. De nuevo el Estado hace una interpretación muy generosa del alcance de su competencia sobre régimen local al amparo del art. 149.1.18 CE. Visión expansiva de una competencia estatal que, hasta hoy y en lo esencial, ha sido bendecida por nuestra jurisprudencia constitucional.

En definitiva, el alcance general de los principios constitucionales del art. 135 CE es esgrimido como cobertura por un legislador estatal que, so pretexto de asegurar su efectividad en las entidades locales, configura una reforma que busca la uniformidad en su aplicación territorial. Voluntad esta manifiestamente visible en el texto de las primeras versiones que se fueron conociendo. No obstante y probablemente como consecuencia de la fuerte oposición de algunas comunidades autónomas, especialmente cuando ya se estaba tramitando el proyecto de ley en las cámaras parlamentarias, comenzaron a incluirse cláusulas que exceptuaban o bien modulaban la aplicación de la ley en ciertos territorios. De este modo, la aplicación uniforme pierde su carácter absoluto y cede espacio a una aplicación diferenciada o asimétrica ${ }^{8}$. La búsqueda del siempre difícil equilibrio entre uniformidad y diversidad reaparece aquí bajo la forma de una geometría variable en la aplicación territorial de la reforma finalmente aprobada.

Las cláusula de excepción o modulación de la aplicación de la ley se recogen en varias de sus disposiciones adicionales. El análisis de cada una de ellas ya justificaría sobradamente un estudio por separado. Limitémonos aquí, pues, a la indicación de cuales son y a una sucinta valoración:

\section{a) Ciudades autónomas de Ceuta y Melilla.}

La disposición adicional cuarta LRSAL establece relevantes "especialidades" para las ciudades autónomas de Ceuta y Melilla. Lo cierto es que esta aplicación diferenciada no ha sido puesta en cuestión habida cuenta la muy peculiar naturaleza de estas dos ciudades, dotadas de un régimen especial encabezado por sus respectivos estatutos de autonomía9 e integrado por las normas de desarrollo dictadas por sus correspondientes Asambleas en virtud del ejercicio de su potestad reglamentaria.

\section{b) Municipios de régimen especial de Madrid y Barcelona.}

La disposición adicional quinta LRSAL tiene como objeto determinar la aplicación de esta ley concretamente en los municipios de Madrid y de Barcelona. Estas dos ciudades, como es sabido, cuentan desde antiguo con un régimen especial de carácter singular. Pues bien, conocedora de esta realidad, la mencionada disposición intenta asegurar la consecución de la finalidad de la LRSAL también en estos territorios, pero con la salvaguarda, en todo lo posible, de sus regímenes propios: "Las disposiciones de esta Ley son de aplicación a los municipios de Madrid y Barcelona, sin perjuicio de las particularidades de su legislación específica y con estricta sujeción a los principios de estabilidad presupuestaria y sostenibilidad financiera".

El tratamiento concedido a estos dos grandes municipios ha variado marcadamente a lo largo del enrevesado proceso de elaboración de la reforma. De la lectura de las sucesivas versiones, podemos diferenciar las siguientes etapas en la evolución del tratamiento ofrecido.

8 De aplicación asimétrica de la LRSAL habla VELASCO CABALLERO, Francisco, "La ley de racionalización y sostenibilidad de la Administración local en el sistema de derecho local”, en Reforma del régimen local. La Ley de racionalización y sostenibilidad de la Administración local: veintitrés estudios (coord.. Manuel J. Domingo Zaballos), Aranzadi, 2014, p. 44.

9 Ley Orgánica 1/1995, de 13 de marzo, del Estatuto de Autonomía de Ceuta y Ley Orgánica 2/1995, de 13 de marzo, del Estatuto de Autonomía de Melilla. 
En los primeros borradores se guarda silencio sobre esta cuestión. En efecto, en ellos no se contiene ninguna referencia específica a Madrid o Barcelona ni en su articulado ni en las disposiciones finales. Ahora bien, con carácter general y, por tanto, con la posibilidad de afectar a sus respectivos regímenes especiales, la disposición derogatoria única establecía: “A la entrada en vigor de esta Ley quedan derogadas cuantas disposiciones de igual o inferior rango se opongan o contradigan lo en ella establecido”.

En una segunda etapa, que arranca con el borrador de 18 de febrero de 2013, se modifica el articulado para incluir alguna referencia concreta a estas ciudades (por ejemplo, en materia de personal o de organización). Pero lo más relevante es que se modifica también la redacción de la disposición derogatoria única, con alusión directa a la afectación de sus regímenes especiales: "A la entrada en vigor de esta Ley quedan derogadas cuantas disposiciones de igual o inferior rango se opongan o contradigan lo en ella establecido. En particular, quedan derogadas (...) todas aquellas disposiciones contrarias a lo previsto en esta Ley contenidas en la Ley 22/2006, de 4 de julio, de Capitalidad y de Régimen Especial de Madrid, y en la Ley 1/2006, de 13 de marzo, por la que se regula el Régimen Especial del Municipio de Barcelona".

Poco tiempo después, a partir del borrador de 21 de mayo de 2013, se abre una tercera etapa con la inclusión en el texto de una disposición adicional cuarta (la que finalmente será la quinta) dedicada íntegra y específicamente a los regímenes especiales de Madrid y Barcelona, con el siguiente tenor: "Las disposiciones de esta Ley son de aplicación a los municipios de Madrid y Barcelona, sin perjuicio de las particularidades de su legislación específica en lo que no se oponga a la misma y con estricta sujeción a los principios de estabilidad presupuestaria y sostenibilidad financiera" ${ }^{\prime \prime}$.

Las dificultades interpretativas ya estaban muy presentes en este momento, puesto que la introducción de esta disposición adicional convivía con el mantenimiento de la disposición derogatoria única y su referencia específica a los regímenes especiales de ambas ciudades. Tuvo aquí una gran influencia el Dictamen de 26 de junio de 2013 del Consejo de Estado sobre el proyecto de ley. El órgano consultivo, en efecto, entra a examinar muy críticamente tanto la disposición adicional cuarta (quinta, en la versión definitiva) como la disposición derogatoria del proyecto de ley, sosteniendo la necesidad de que ambas sean profundamente reformuladas ya que: "lo natural es que las normas jurídicas de naturaleza particular difieran de las normas generales referidas a la misma materia. Por ello, la precisión según la cual las leyes particulares de los Municipios de Madrid y de Barcelona cuya vigencia expresamente se mantiene deben aplicarse en cuanto no se opongan a la nueva Ley constituye una determinación poco coherente y generadora de confusión. Por tal razón, se entiende necesario que en esta disposición adicional se suprima el inciso «en lo que no se oponga a la misma». Por lo mismo, en la disposición derogatoria debería eliminarse su contenido final, referido a las Leyes 22/2006 y 1/2006. Esto es, cuanto sigue a partir de las palabras «... así como todas a aquéllas...»»". Estas indicaciones serán acogidas en la versión final del texto legislativo.

La redacción de la disposición adicional quinta LRSAL es manifiestamente mejorable. Ateniendo a su tenor literal podemos extraer las siguientes conclusiones.

Por lo pronto, la regla general es que la totalidad de la regulación contenida en la LRSAL es aplicable a estas dos grandes ciudades: "Las disposiciones de esta Ley son de aplicación a los municipios de Madrid y Barcelona”. Conviene advertir, además, que se trata de una aplicación directa. No estamos, pues, ante una aplicación supletoria, a diferencia de lo que establecen, por ejemplo, los arts. 160 y 161 del Texto Refundido de la Ley de Haciendas Locales (aprobado por Real Decreto legislativo 2/2004, de 5 de marzo).

Por excepción, no será de aplicación a estos dos municipios la parte de la regulación contenida en la LRSAL que sea incompatible con las particularidades de su régimen especial: "sin perjuicio de las particularidades de su legislación específica”. Pudiera parecer que adquiere aquí gran importancia fijar con precisión cuales sean estas "particularidades" del régimen especial de estos municipios. Pero la realidad es que, por su misma definición, todas las disposiciones de la legislación especial que no coincidan con la legislación general pueden ser calificadas como particularidades.

El límite a la posibilidad de exceptuar la aplicación de las bases contenidas en la LRSAL, en el caso de estos dos grandes municipios, es la sumisión rigurosa a los principios de estabilidad presupuestaria y sostenibilidad financiera: "con estricta sujeción a los principios de estabilidad presupuestaria y sostenibilidad financiera”. En el fondo, lo que viene a establecerse es que el límite lo constituye el nuevo contenido del art. 135 CE. No es fácil interpretar el alcance de este límite, referido a dichos principios 
constitucionales. Ciertamente la exposición de motivos de la propia ley justifica la totalidad de la reforma en la necesidad de desarrollar y aplicar esos principios en la administración local. Pero una interpretación extensiva de este criterio llevaría al absurdo de vaciar completamente de contenido la disposición adicional quinta. Por ello, parece razonable proceder a una interpretación más restrictiva. De este modo, cabría admitir que solamente estaría justificado que fueran un límite a la aplicación preferente de la legislación especial aquellas afectaciones de la ley general sobre la ley especial que pudieran acreditar una suficiente conexión, directa e inmediata, por necesarias, con la efectividad de los principios de estabilidad presupuestaria y sostenibilidad financiera.

\section{c) Comunidad Autónoma del País Vasco y Comunidad Foral de Navarra.}

Dentro de las comunidades autónomas, las que disfrutan de una más generosa cláusula de aplicación diferenciada de la ley son el País Vasco y Navarra (disposiciones adicionales primera y segunda LRSAL, respectivamente). En efecto, en ellas se afirma que "se aplicará" a la Comunidad Autónoma del País Vasco (apartado primero de la disposición adicional primera) o bien a la Comunidad Foral de Navarra (apartado primero de la disposición adicional segunda) "en los términos establecidos en el artículo 149.1 .14 y 18 y disposición adicional primera de la Constitución, sin perjuicio de las particularidades que resultan de la Ley Orgánica 3/1979, de 18 de diciembre, por la que se aprueba el Estatuto de Autonomía para el País Vasco [o, en el caso de Navarra, de la Ley Orgánica 13/1982, de 10 de agosto, de Reintegración y Amejoramiento del Régimen Foral de Navarra], de la disposición final tercera de la Ley Orgánica 2/2012, de 27 de abril, de Estabilidad Presupuestaria y Sostenibilidad Financiera, y de las demás normas que actualicen los derechos históricos de los territorios forales".

En nuestra opinión, el análisis de estas disposiciones adicionales debe arrancar del modo en que se aborda la cuestión relativa a la forma o alcance de la aplicación de la LRSAL en estas dos comunidades autónomas. Pues bien, se aborda con la advertencia de que dicha aplicación, en estos casos, debe hacerse "en los términos establecidos en el artículo 149.1.14 y 18 y disposición adicional primera de la Constitución”. Dicho de otra manera, la aplicación de la LRSAL en estos territorios debe llevarse a cabo en el punto de equilibrio entre los títulos competenciales utilizados por el Estado para aprobar la reforma (los recogidos en los citados arts. 149.1.14 y 149.1.18 de la CE, según reconoce la propia disposición final quinta LRSAL) y el amparo constitucional de los derechos históricos de los territorios forales (disposición adicional primera (E). En suma, el legislador básico, a través de estas disposiciones adicionales, intenta delimitar la aplicación de su norma en el País Vasco y en Navarra buscando conjugar dos imperativos constitucionales: por un lado, la atribución constitucional de títulos competenciales al Estado y, por otro, la garantía constitucional de la foralidad. El primero favorece la aplicación uniforme de la ley. El segundo, en cambio, asegura la diversidad o asimetría aplicativa en los territorios forales.

El punto de equilibrio entre ambos mandatos constitucionales es encontrado por ambas disposiciones adicionales estableciendo una regla general y seguidamente una excepción. La regla general es la aplicabilidad de la LRSAL a estas dos comunidades autónomas. En ambos preceptos, efectivamente, se arranca con la afirmación de que "esta ley se aplicará" en ellas. Pero a continuación se establece la excepción a esa regla: la aplicación de la LRSAL se realizará "sin perjuicio de las particularidades" que resulten del Estatuto de Autonomía del País Vasco o de Navarra, de la disposición final tercera de la Ley Orgánica 2/2012, de 27 de abril, de Estabilidad Presupuestaria y Sostenibilidad Financiera (en adelante, LOEPSF)" y, en general, "de las demás normas que actualicen los derechos históricos de los territorios forales"12. En conclusión, se condiciona la aplicación de la LRSAL a su no contradicción con las normas estatutarias y, en general, con todas aquellas que integren su régimen foral actualizado. O lo que es lo mismo, se reconoce la aplicación preferente de este último conjunto normativo sobre los preceptos contenidos en la LRSAL.

\section{d) Comunidad Autónoma de Aragón.}

La Comunidad Autónoma de Aragón cuenta también con una cláusula específica contenida en la disposición adicional tercera, apartado tercero, LRSAL. Se trata de una poco clara disposición en la que se

11 Esta disposición final tercera, bajo la rúbrica de "Haciendas Forales", condiciona la aplicación de la LOEPSF en estos territorios. En relación con Navarra, "en virtud de su régimen foral”, el apartado primero dispone que la ley se aplicará "conforme a lo dispuesto en el Convenio Económico entre el Estado y la Comunidad Foral de Navarra”. Y respecto al País Vasco, de nuevo "en virtud de su régimen foral”, el apartado segundo afirma que la aplicación de la ley "se entenderá sin perjuicio de lo dispuesto en la Ley del Concierto Económico".

12 La disposición adicional primera CE, en su apartado segundo, establece que: "La actualización general de dicho régimen foral [derechos históricos de los territorios forales] se llevará a cabo, en su caso, en el marco de la Constitución y de los Estatutos de Autonomía”. 
afirma, de entrada, que la aplicación de la LRSAL en ese territorio deberá hacerse "teniendo en cuenta el régimen especial de organización institucional previsto en su Estatuto de Autonomía”. Esa especialidad, aunque no aparezca concretada, hemos de entenderla referida al nivel supramunicipal, habida cuenta de que esta norma estatutaria prevé la coexistencia de provincia y comarca.

Queda por aclarar el significado y alcance que deba darse a ese "tener en cuenta" a través del cual se articula la relación aplicativa entre la LRSAL y el Estatuto aragonés. En cualquier caso, y a pesar de lo deficiente de la redacción, el precepto deja claro que la actuación autonómica ("la Comunidad Autónoma aplicará las competencias previstas en esta Ley en los distintos niveles de la administración”) deberá hacerse necesariamente "con sujeción a la Constitución, al contenido básico de esta Ley y a los principios de estabilidad presupuestaria, sostenibilidad financiera y racionalización de las estructuras administrativas". Si nos quedamos con una interpretación literal, poco margen queda a la especialidad, puesto que "tener en cuenta" el Estatuto debe ser compatible con la aplicación de la totalidad -pues no se limita o circunscribe- del “contenido básico” de la LRSAL. Y, por si aún quedase alguna duda, debe serlo con el respeto de los principios de estabilidad presupuestaria, sostenibilidad financiera y racionalización de las estructuras administrativas que son, precisamente, los objetivos que justifican la aprobación de la ley y que, por consiguiente, explican la totalidad de sus preceptos.

\section{e) Islas Canarias e Illes Balears.}

La disposición adicional decimosexta LRSAL contiene dos cláusulas dedicadas específica y respectivamente a las Islas Canarias (apartado primero) y a las Illes Balears (apartado segundo). En ambos casos, se parte de que la LRSAL se aplicará a los cabildos insulares canarios y a los consejos insulares baleares, pero "en los términos previstos en su legislación específica”. No se aclara cual sea esa "legislación específica”, aunque sin duda cabrá incluir sus respectivas normas estatutarias. En cualquier caso, la modulación de la aplicación de la LRSAL en los territorios insulares encuentra el límite habitual: "con estricta sujeción a los principios de estabilidad presupuestaria y sostenibilidad financiera".

\section{f) Comunidades Autónomas con competencias exclusivas en materia de régimen local.}

Hasta aquí hemos analizado cláusulas referidas específicamente a comunidades autónomas concretas. La LRSAL contiene además, sin embargo, otras referidas genéricamente a todas las comunidades o bien a un conjunto indeterminado de ellas delimitado por algún rasgo en común.

La primera es la contenida en la disposición adicional tercera, apartado primero, LRSAL. En ella se afirma que los preceptos de esta ley "son de aplicación a todas las comunidades autónomas". Aplicación que debe hacerse, no obstante, "sin perjuicio de sus competencias exclusivas en materia de régimen local asumidas en sus estatutos de autonomía”. Ahora bien, con el límite de que tendrá lugar "en el marco de la normativa básica estatal y con estricta sujeción a los principios de estabilidad presupuestaria, sostenibilidad financiera y racionalización de las estructuras administrativas".

Nos encontramos, otra vez, ante una disposición cuya recto significado es un verdadero misterio. En efecto, la regla general parece ser la plena aplicación en el común de las comunidades autónomas de todo el contenido de la LRSAL. Ahora bien, esa regla encuentra como excepción (“sin perjuicio"), en el caso de aquellas comunidades que las tengan, las competencias exclusivas en materia de régimen local atribuidas por sus respectivos estatutos. Lo que implicaría la no aplicación, en esos territorios, de aquellos contenidos de la ley que recaigan sobre cuestiones incluidas en dicha materia competencial. Pero tal cosa no es así, puesto que el confuso precepto impone un límite a la excepción: la operación debe hacerse "en el marco de la normativa básica estatal". Y como la práctica totalidad de la LRSAL tiene este carácter, hemos de entender que ha de tener lugar "en el marco" de la propia LRSAL. Para disipar cualquier duda que pudiera existir, se añade finamente el límite habitual: "con estricta sujeción a los principios de estabilidad presupuestaria, sostenibilidad financiera y racionalización de las estructuras administrativas”.

\section{g) Comunidades Autónomas con un sistema institucional propio.}

La disposición adicional tercera, apartado segundo, LRSAL se refiere al conjunto de "comunidades autónomas con un sistema institucional propio". Aquí tienen cabida algunas comunidades que cuentan ya con una cláusula específica, como es el caso de los cabildos insulares de Canarias (disposición adicional decimosexta, apartado primero, LRSAL), de los consejos insulares de las Illes Balears (disposición adicional decimosexta, apartado segundo, LRSAL) y de las comarcas de Aragón (disposición adicional tercera, apartado tercero, LRSAL). Pero la alusión que se hace a la existencia de un "sistema institucional propio" 
nos parece un guiño a Cataluña que, sorprendentemente, no cuenta con ninguna cláusula específica. En efecto, el art. 2.1 del Estatuto catalán define la Generalitat como "el sistema institucional en que se organiza políticamente el autogobierno de Cataluña". Sistema institucional que está compuesto por las instituciones de nivel autonómico (art. 2.2) y, además, por los entes locales catalanes: "los municipios, las veguerías, las comarcas y los demás entes locales que las leyes determinen” (art. 2.3).

La especialidad prevista en estos casos consiste en que "las referencias de esta ley a las diputaciones provinciales se entenderán efectuadas a los entes locales supramunicipales previstos en los correspondientes estatutos de autonomía a los que se atribuyen competencias en materia de asistencia y cooperación a los municipios y prestación de servicios públicos locales". Como bien se ha observado, esta disposición debe interpretarse de una manera que sea conforme con la salvaguarda de la autonomía provincial, derivada directamente de la Constitución y cuyo núcleo esencial, según ha afirmado nuestro Tribunal Constitucional, es precisamente la función de asistencia y cooperación con los municipios ${ }^{13}$.

\section{h) Comunidades Autónomas con organización comarcal.}

En último lugar, la disposición adicional sexta LRSAL contiene una cláusula referida conjuntamente a aquellas comunidades autónomas en cuyos estatutos de autonomía se prevea una "organización comarcal". Hay que entenderla aplicable, por tanto, no únicamente a Aragón, que ya cuenta con una cláusula propia (disposición adicional tercera, apartado tercero, LRSAL), sino también a aquellas otras comunidades que cuenten con comarcas, como es el caso de Cataluña (arts. 83.2 y 92 del Estatuto catalán) y de Castilla y León, con el caso singular de la Comarca del Bierzo (art. 46 del Estatuto castellano-leonés).

La especialidad permite salvar la peculiaridad estatutaria en estos territorios, puesto que la aplicación de la LRSAL debe hacerse "respetando la organización comarcal en aquellas comunidades autónomas cuyos estatutos de autonomía tenga atribuida expresamente la gestión de servicios supramunicipales".

Hasta aquí la sintética exposición de las disposiciones adicionales que hacen efectiva la aplicación diferenciada o asimétrica de la LRSAL. Una valoración de conjunto nos permite destacar las siguientes notas sobre ellas:

a) Extensión de la diversidad: gran número de cláusulas y ausencias significativas.

Las disposiciones adicionales analizadas contienen un gran número de cláusulas que excepcionan o modulan la aplicación de la ley desde la perspectiva territorial. Este hecho llama la atención si lo comparamos con los primeros borradores que vieron la luz y que pretendían una aplicación uniforme de la ley. Algunas de estas cláusulas se refieren a ciudades (las autónomas de Ceuta y Melilla, por un lado, y los grandes municipios de Madrid y Barcelona, por el otro), mientras que el resto lo hacen a comunidades autónomas, ya sea específicamente a una en concreto, a todas en general o bien a un conjunto de ellas delimitado por algún rasgo en común. A pesar de las muchas disposiciones adicionales dedicadas a la aplicación diferenciada de la LRSAL, se nota alguna ausencia. En concreto, y como ya hemos apuntado, sorprende que haya una disposición de aplicación concreta al municipio de Barcelona y no, en cambio, a Cataluña, a pesar de la evidente peculiaridad de su sistema institucional local y del hecho notorio de que ha sido la reforma de su estatuto el modelo seguido por las modificaciones estatutarias posteriores.

b) Deficiente técnica normativa y confusión: los principios de estabilidad presupuestaria y de sostenibilidad financiera como núcleo duro en la aplicabilidad de la ley.

En general, se aprecia en todas estas disposiciones adicionales el empleo de una muy deficiente técnica normativa. La mala redacción genera confusión y da lugar al nacimiento de no pocas dudas. En algunos casos, la interpretación literal de los preceptos conduce a sinsentidos lógicos o conclusiones imposibles. Todo apunta, pues, a que la conflictividad hará acto de presencia. Lo único que queda claro, a nuestro parecer, es la voluntad firme del legislador de que la articulación a la que se llegue entre la aplicación de la LRSAL y el respeto a las especialidades del territorio correspondiente, conlleve siempre y necesariamente el respeto a los principios de estabilidad presupuestaria y sostenibilidad financiera. De ahí la reiteración de esta coletilla en las mencionadas disposiciones adicionales. Lo que resulta coherente con la finalidad buscada con la aprobación de la ley y con el nuevo contenido dado al art. 135 CE.

13 VELASCO CABALLERO, Francisco, "La ley de racionalización y sostenibilidad de la Administración local en el sistema de derecho local",ob. cit., p. 49. 
c) Relación entre la LRSAL y los estatutos de autonomía: papel que corresponde al legislador estatal.

La interpretación de estas disposiciones adicionales conduce, en realidad, al problema de la relación existente entre la LRSAL y los estatutos de autonomía. Y ello en un doble sentido. De entrada, se plantea la cuestión de articular la aplicación de la LRSAL y las competencias de las comunidades autónomas sobre régimen local atribuidas por el correspondiente estatuto, sobre todo cuando lo que se atribuye son competencias exclusivas sobre dicha materia. A poco que se piense, estamos ante la clásica cuestión de la relación entre la competencia constitucional básica del Estado y la competencia estatutaria de la comunidad autónoma (que puede ser exclusiva) sobre las materias relativas a organización territorial y régimen local. En segundo lugar, surge también la cuestión de articular la aplicación de la LRSAL con la aplicación directa de los estatutos de autonomía. Porque, en efecto, los nuevos estatutos contienen una regulación más densa de los gobiernos locales, de manera que algunos de sus preceptos pueden entrar ahora en contradicción con lo establecido en la mencionada ley. Desde luego no es este el lugar para analizar con detalle estas cuestiones. Baste con remitirnos a la copiosa bibliografía publicada a raíz de la reforma estatutaria catalana y de la STC 31/2010, de 28 de junio, recaída sobre ella. Simplemente nos permitimos recordar aquí que la solución a estos problemas no queda en manos del legislador estatal. En concreto, no corresponde al legislador básico de régimen local determinar la relación de sus normas con los estatutos de autonomía, como tampoco precisar el contenido y alcance de la competencia autonómica sobre esa materia. En caso de conflicto, la solución deberá venir de la mano del Tribunal Constitucional, en aplicación de las normas sobre la producción jurídica. Idea esta importante, como bien se entenderá, a la hora de precisar la eficacia de las disposiciones adicionales examinadas de la LRSAL ${ }^{14}$.

\section{EL RECHAZO GENERALIZADO DE LA LEY}

Hacer realidad los mandatos contenidos en la ley se dificulta también por la amplia oposición que ha encontrado durante su gestación y, tras su aprobación, por las resistencias que debe vencer para hacer efectiva su aplicación. Estamos ante un rechazo muy generalizado:

a) Crítica de la doctrina científica.

Desde un buen inicio, la mayoría de la doctrina especializada mostró una actitud crítica tanto en relación con la forma en que se estaba llevando a cabo una reforma tan relevante como sobre los contenidos que aparecían en los sucesivos borradores que iban viendo la luz. Fiel testigo de este debate han sido los numerosos estudios publicados durante este período, entre los que destacamos aquellos recogidos en los números correspondientes del Anuario del Gobierno Local.

En un intento constructivo de mejorar la iniciativa, se emitió un "Informe sobre el Anteproyecto de Ley de Racionalización y Sostenibilidad de la Administración Local”, en abril de 2013, por la Asociación Española de Profesores de Derecho Administrativo y a petición del Instituto Nacional de Administración Pública. Como bien señala en su presentación el profesor Fernando López Menudo, Presidente de la mencionada Asociación, el objeto del informe era proceder a una valoración jurídica del texto, siendo suscrito por los profesores Martín Bassols Coma, Tomás Font i Llovet, Eloisa Carbonell Porras y Marcos Almeida Cerreda ${ }^{15}$.

Por lo demás, las críticas doctrinales se vieron reforzadas por los también muy críticos pronunciamientos de algunas instituciones de perfil técnico e independiente. Sirvan de ejemplo el Informe 88/13, de 13 de marzo de 2013, del Consejo Nacional de la Competencia o bien el Dictamen 567/2013, de 26 junio, del Consejo de Estado.

b) Crítica de los gobiernos locales.

Los destinatarios últimos de la reforma, esto es, lo gobiernos locales, mostraron, de manera incisiva y reiterada, individualmente y a través de sus organizaciones representativas, su rechazo a la reforma proyectada. Varios motivos confluyeron para que tal cosa tuviera lugar.

14 En sentido similar se pronuncia VELASCO CABALLERO, Francisco, "La ley de racionalización y sostenibilidad de la Administración local en el sistema de derecho local",ob. cit., pp. 47 a 50.

15 Los citados profesores fueron los protagonistas de la ponencia "La planta del gobierno local" que tuvo lugar en el VIII Congreso de Profesores de Derecho Administrativo, celebrado en la Universidad de Alicante los días 8 y 9 de febrero de 2013 . Sus intervenciones han sido recogidas en el libro "La planta del gobierno local: actas del VIII Congreso de la Asociación Española de Profesores de Derecho Administrativo", Fundación Democracia y Gobierno Local, 2013. Un análisis de este informe en FONT i LLOVET, Tomás y GALÁN GALÁN, Alfredo, “Racionalización y sostenibilidad de la Administración local: ¿es ésta la reforma?”, en Anuario del Gobierno Local 2012, Fundación Democracia y Gobierno Local Instituto de Derecho Público, 2013, pp. 23-27. 
De entrada, porque no se trataba de la reforma largamente reclamada desde el ámbito local. Quedó claro desde el principio que la iniciativa no pretendía resolver los problemas que viene padeciendo el mundo local, sino que, por el contrario, se marcó como objetivo dar solución a otros problemas que presumiblemente eran causados por los gobiernos locales, en el marco genérico de la necesidad de contener el gasto público como medio para luchar contra la crisis económica. Para la reforma, en definitiva, los gobiernos locales no son tanto las víctimas, sino los responsables de las disfunciones que aborda. Porque lo cierto es que tanto la planificación como la ejecución de la reforma local se han pensado desde arriba. Dicho al contrario, no es una reforma que nazca desde abajo, fruto de las reivindicaciones del mundo local, de manera que finalmente lleguen a lo alto para ser recogidas por un legislador sensible a dichas peticiones. Antes al contrario: el diagnóstico de la situación y la selección de las medidas a adoptar son labores cruciales que han sido realizadas en la soledad del ministerio y, probablemente, por manos expertas en economía. Porque, como decimos, la reforma local no pretende resolver los problemas que padecen los gobiernos locales, sino los problemas que, al menos en parte, se cree que han sido generados por ellos. No debe extrañar, pues, que en el texto de la nueva ley no se ofrezca respuesta a las denuncias de todo tipo, sobre carencias y necesidades de la vida local, que, desde hace largo tiempo, vienen haciéndose desde la doctrina y, sobre todo, desde las asociaciones representativas de entes locales. Sencillamente no es el objeto de la ley: no es el propósito de la reforma. La satisfacción de esas expectativas tendrá que esperar ${ }^{16}$.

El rechazo por los gobiernos locales se explica también por la creencia generalizada entre ellos de lo injusto que es culpabilizarles de un pecado que no habían cometido o, si acaso, únicamente de forma venial. En efecto, en el origen de la reforma local se encuentra la pinza entre crisis económica y presión de la Unión Europea. No es una novedad que el legislador actúe condicionado por las circunstancias de una realidad que fundamentan su intervención a la vez que limitan su margen de maniobra. Esto es lo que ha ocurrido, en esta ocasión de un modo muy intenso y evidente, con la reforma local. La existencia misma y el contenido de la LRSAL solamente se explican situadas en un contexto económico concreto: el de una aguda y prolongada crisis económica que ha motivado un duro ajuste de las cuentas públicas, por la vía principalmente del recorte del gasto de las administraciones. La preocupación no es tanto mejorar como ahorrar. Sirva de ejemplo el "Programa Nacional de Reformas del Reino de España del año 2013", aprobado por el Gobierno español, donde se sostiene que la reforma local "supondrá un ahorro estimado de 8.000 millones de euros entre los años 2014 a 2015 ”. Eso sí, sin mayor justificación de dicha afirmación. A la crisis económica debe sumarse, como detonante de la reforma que estamos comentando, una indisimulada presión de la Unión Europea. No debe olvidarse que sobre la cabeza de la economía española y, claro está, sobre la de los responsables políticos internos de gobernarla, se balanceaba la amenazadora espada de un rescate europeo. Para sortear el riesgo de intervención o, al menos, para dulcificar su grado, se inició un desigual diálogo de las autoridades españolas con las instancias europeas y, en general, con aquellas financieras de ámbito internacional. Era vital lanzar con urgencia un mensaje claro, tranquilizador para nuestros acreedores, de que se estaban adoptando las medidas necesarias para asegurar la sostenibilidad de las cuentas públicas. En realidad, dada la impronta psicológica que caracteriza actualmente las decisiones económicas en los mercados, tan importante resultaba la forma como el fondo de las medidas a adoptar: la visibilidad, incluso la espectacularidad de las medidas refuerzan la credibilidad del compromiso asumido. A nadie escapa que uno de los primeros y relevantes frutos de dicho compromiso fue la reforma expeditiva del art. $135 \mathrm{CE}$, de 27 de septiembre de 2011, desarrollada por la Ley Orgánica 2/2012, de 27 de abril, de Estabilidad Presupuestaria y Sostenibilidad Financiera. Pero también lo fue el anuncio de una reordenación global del nivel local de gobierno que, al menos en las primeras versiones de la reforma, se traduciría en la desaparición de un gran número de administraciones y una profunda reordenación del sistema competencial, consiguiéndose, de este modo, un notable ahorro para las arcas públicas ${ }^{17}$.

Por último, la posición contraria de los gobiernos locales a la reforma se explica también ante el temor de que con ella se vulnerase la autonomía local ${ }^{18}$. De hecho, el Municipio de Barcelona junto a otros muchos ha planteado ante el Tribunal Constitucional un conflicto en defensa de la autonomía

16 Sobre esta cuestión, más en profundidad, FONT i LLOVET, Tomás y GALÁN GALÁN, Alfredo, “La reordenación de las competencias municipales: ¿una mutación constitucional?", ob. cit., p. 15.

17 De nuevo, para una mayor profundización, FONT i LLOVET, Tomás y GALÁN GALÁN, Alfredo, “La reordenación de las competencias municipales: ¿una mutación constitucional?”, ob. cit., pp. 13-15.

18 Un análisis sobre esta posible vulneración en FONT i LLOVET, Tomás y GALÁN GALÁN, Alfredo, “Racionalización y sostenibilidad de la Administración local: ¿es ésta la reforma?”, ob. cit., pp. 17-18; y también en el citado Informe sobre el Anteproyecto de Ley de Racionalización y Sostenibilidad de la Administración Local, de abril de 2013, emitido por la Asociación Española de Profesores de Derecho Administrativo a petición del Instituto Nacional de Administración Pública. 
local en relación con la LRSAL. A propósito, el Dictamen 338/2014, de 22 de mayo, del Consejo de Estado, sostiene que existen fundamentos jurídicos suficientes para sostener el mencionado conflicto en relación con los arts. 26.2, 116 ter y disposición adicional decimosexta LBRL en la redacción dada por la LRSAL. Quedamos, pues, a la espera de lo que diga nuestra corte constitucional. Nos limitamos a señalar aquí, sin embargo, que en su sentencia deberá buscar necesariamente un difícil equilibrio entre la autonomía local, constitucionalmente garantizada, y los principios de estabilidad presupuestaria y sostenibilidad financiera, reforzados en el nuevo art. 135 CE. Dicho de otro modo, nuestro modelo de gobierno local ha cambiado: ya no puede basarse únicamente en el pilar del reconocimiento y aseguramiento de la autonomía local, sino que este dato constitucional debe ahora convivir con otro de igual rango, a saber, las exigencias de los citados principios vinculados con la eficiencia económica. En suma, autonomía local y eficiencia económica deben convivir sin excluirse, pero también sin ignorarse ${ }^{19}$.

c) Crítica de las comunidades autónomas.

Las comunidades autónomas como regla también se han opuesto a la reforma local. Han enarbolado la bandera de la defensa de la autonomía de sus entidades locales, pero principalmente actúan ante lo que consideran una invasión estatal de sus competencias. De concretar su reacción nos ocupamos en el siguiente apartado.

\section{LA TORTUOSA APLICACIÓN DE LA LEY POR LAS COMUNIDADES AUTÓNOMAS}

La aprobación por el Estado de la LRSAL ha originado un fuerte rechazo en la mayoría de las comunidades autónomas. Oposición que se ha articulado de dos formas distintas y complementarias: mediante su impugnación ante el Tribunal Constitucional y, a la espera de su pronunciamiento, a través de una aplicación obstativa o reinterpretadora de los contenidos de la ley ${ }^{20}$ :

a) Impugnación autonómica de la LRSAL ante el Tribunal Constitucional.

Algunas -no pocas- comunidades autónomas han interpuesto recurso de inconstitucionalidad contra diversos preceptos de la LRSAL. En concreto, lo han promovido: la Asamblea de Extremadura (núm. 17922014); el Consejo de Gobierno de Andalucía (núm. 1959-2014) y el Parlamento de Andalucía (núm. 20032014); el Consejo de Gobierno del Principado de Asturias (núm. 1995-2014); el Parlamento de Cataluña (núm. 1996-2014) y el Gobierno de Cataluña (núm. 2006-2014); el Parlamento de Navarra (núm. 2001-2014); y el Gobierno de Canarias (núm. 2043-2014) ${ }^{21}$.

No tenemos la posibilidad de entrar a examinar a fondo los preceptos recurridos y la argumentación que sostiene las impugnaciones. Baste con señalar las líneas comunes, que son principalmente las dos siguientes. En primer lugar, la vulneración que la ley produce de la autonomía de sus gobiernos locales. Aunque lo cierto es que no deja de ser algo colateral en relación con la principal vía argumental, a saber: la defensa de las propias competencias autonómicas ante la extralimitación estatal ${ }^{22}$. En este punto es de interés reflexionar acerca del impacto que tienen los principios de estabilidad presupuestaria y sostenibilidad financiera no solamente en la reinterpretación del alcance de la autonomía local, sino también sobre el reparto de competencias entre estado y comunidad autónoma en las materias relativas a la organización territorial y el régimen local. Es verdad que el art. 135 CE no constituye un título atributivo de competencias del Estado, pero resulta innegable que bajo su cobertura, y con una nueva interpretación de los títulos estatales del art. 149.1 CE, se está dictando una incesante y expansiva normativa estatal de contenido económico que ocupa espacios antes reservados al legislador autonómico.

b) Obstaculización o reinterpretación en la aplicación autonómica de la LRSAL.

El espíritu autonómico contrario a lo ordenado por la LRSAL se hace evidente a la hora de proceder a su aplicación. Contrariedad que se manifiesta de formas distintas. Por lo pronto, y en algunas comunidades autónomas, no dictando normas autonómicas de desarrollo de las bases contenidas en la ley estatal.

19 Más desarrollado en FONT i LLOVET, Tomás y GALÁN GALÁN, Alfredo, “La reordenación de las competencias municipales: ¿una mutación constitucional?", ob. cit., p. 20.

20 Esta idea ha sido destacada por Marcos Almeida Cerrada en su ponencia “El papel de las comunidades autónomas y la reinterpretación de la LRSAL", realizada en Barcelona el 5 de noviembre de 2014, en el Curso “La aplicación de la reforma de los gobiernos locales", dirigido por Tomás Font i Llovet, en el marco de los cursos organizados por el Consorcio de la Universidad Internacional Menéndez Pelayo de Barcelona.

21 A estas impugnaciones debe sumarse el recurso de inconstitucionalidad núm. 2002-2014, promovido por más de cincuenta diputados, integrantes de los Grupos Parlamentarios Socialista; IU, ICV-EUIA, CHA, La Izquierda Plural; Unión Progreso y Democracia; y Mixto. Así como el ya mencionado conflicto en defensa de la autonomía local núm. 4292-2014.

22 FONT i LLOVET, Tomás y GALÁN GALÁN, Alfredo, “Racionalización y sostenibilidad de la Administración local: ¿es ésta la reforma?”, ob. cit., pp. 18-20. 
O bien limitándose a aprobar disposiciones aclaratorias carentes, al menos formalmente, de naturaleza normativa. Finalmente, en otros casos, dictándose normas autonómicas que reinterpretan los preceptos contenidos en la ley estatal, obstaculizando así que puedan aplicarse en su recto sentido originario. Un ejemplo puede servir para ilustrar esta última afirmación. Como es sabido, para que las entidades locales puedan ejercer competencias distintas de las propias y de las atribuidas por delegación (las denominadas "competencias impropias" en las primeras versiones del texto legal), el nuevo art. 7.4 LBRL exige un informe previo de la administración competente por razón de la materia en el que se señale la inexistencia de duplicidades. Pues bien, el desarrollo de este informe en muchas comunidades autónomas suaviza su impacto cuando no lo neutraliza por completo. Así, en algunos supuestos, con base en la literalidad del precepto, que habla de "nuevas competencias", se concluye que el régimen del art. 7.4 LBRL no será de aplicación a las competencias que los entes locales vengan ya ejerciendo. Operará, pues, únicamente de cara al futuro ${ }^{23}$. En otros casos, en cambio, se considera que corresponde a los propios entes locales hacer la valoración acerca de si los servicios que vienen prestando incurren en duplicidad, de manera que si el juicio es negativo no será preciso solicitar autorización alguna a ninguna otra administración ${ }^{24}$.

La LRSAL es principalmente una norma estatal de carácter básico, dictada al amparo del título competencial sobre régimen local implícito en el art. 149.1.18 CE (disposición final quinta LRSAL). Por tanto, y siguiendo las reglas generales de distribución de competencias, lo que procede tras su aprobación es el desarrollo normativo autonómico de sus preceptos. Como ya hemos advertido, sin embargo, las comunidades autónomas han afrontado esta labor -aquellas que lo han hecho- con la aprobación de muy dispares disposiciones. En el momento en que redactamos este trabajo, lo existente puede resumirse así:

a) Mediante la aprobación de una ley autonómica:

- Ley gallega 5/2014, de 27 de mayo, de medidas urgentes derivadas de la entrada en vigor de la LRSAL.

- Ley riojana $2 / 2014$, de 3 de junio, de medidas para la garantía y la continuidad de los servicios públicos en la Comunidad autónoma de La Rioja.

- Ley madrileña 1/2014, de 25 de julio, de adaptación del régimen local de la Comunidad de Madrid a la LRSAL.

b) Mediante la aprobación de un decreto-ley autonómico:

- Decreto-ley castellano-leonés $1 / 2014$, de 27 de marzo, de medidas urgentes para la garantía y la continuidad de los servicios públicos en Castilla y León derivado de la entrada en vigor de la LRSAL.

- Decreto-ley andaluz 7/2014, de 20 de mayo, por el que se establecen medidas urgentes para la aplicación de la LRSAL.

- Decreto-ley extremeño 3/2014, de 10 de junio, por el que se modifica la Ley 17/2010, de 22 de diciembre, de mancomunidades y entidades locales menores de Extremadura.

- Decreto-ley catalán 3/2014, de 17 de junio, por el que se establecen medidas urgentes para la aplicación en Cataluña de la LRSAL. Quedó derogado tras su falta de convalidación por el parlamento autonómico. En su sustitución se dictó el Decreto-ley catalán 4/2014, de 22 de julio, por el que se establecen medidas urgentes para adaptar los convenios, los acuerdos y los instrumentos de cooperación suscritos entre la Administración de la Generalitat y los entes locales de Cataluña a la disposición adicional novena de la LRSAL.

- Decreto-ley murciano 1/2014, de 27 de junio, de medidas urgentes para la garantía y la continuidad de los servicios públicos en la Comunidad Autónoma de la Región de Murcia, derivado de la entrada en vigor de la LRSAL.

- Decreto-ley balear 2/2014, de 21 de noviembre, de medidas urgentes para la aplicación a las Illes Balears de la LRSAL.

23 Así, art. 3 de la Ley gallega 5/2014, de 27 de mayo, de medidas urgentes derivadas de la entrada en vigor de la LRSAL.

24 Así, art. 2.3 y 4 del Decreto-ley andaluz 7/2014, de 20 de mayo, por el que se establecen medidas urgentes para la aplicación de la LRSAL. Y también art. 4.1 del Decreto asturiano 68/2014, de 10 de julio, por el que se regula el procedimiento para la obtención de los informes previstos en el artículo 7.4 de la LBRL. 
c) Mediante la aprobación de una norma autonómica de rango reglamentario.

Aquí se sitúa el Decreto asturiano 68/2014, de 10 de julio, por el que se regula el procedimiento para la obtención de los informes previstos en el artículo 7.4 LRSAL.

d) Mediante la aprobación de otros instrumentos de carácter interpretativo o aclaratorio:

- Circular vasca de 11 de marzo de 2014, de la Directora de Relaciones con las Administraciones Locales y Registros Administrativos, referente al sistema de ordenación de las competencias municipales y al régimen foral vasco, tras la entrada en vigor de la LRSAL.

- Circular castellano-leonesa de 1 de abril de 2014, de la Viceconsejera de Administración y Gobierno del Territorio, relativa al sistema competencial y otras cuestiones derivadas de la entrada en vigor de la LRSAL.

- Nota explicativa catalana de 16 de abril de 2014, de la Secretaría de Cooperación y Coordinación de las Administraciones locales sobre la aplicación en Cataluña de determinados aspectos de la LRSAL.

- Circular aragonesa 1/2014, de 28 de abril, de la Dirección General de la Administración Local del Gobierno de Aragón, sobre el régimen jurídico competencial de los municipios aragoneses tras la entrada en vigor de la LRSAL que modifica la LBRL.

- Circular valenciana de 18 de junio de 2014, de la Dirección General de Administración Local, sobre el nuevo régimen competencial contemplado en la LRSAL.

A la vista de la aplicación de la LRSAL que están llevando a cabo las comunidades autónomas, concretada hasta el momento en las disposiciones arriba enumeradas, podemos hacer la siguiente valoración:

a) Debe tenerse presente el distinto punto de partida que tienen las comunidades autónomas, habida cuenta de la ya examinada aplicación territorial diferenciada o asimétrica de la LRSAL. Por ello, resulta no solamente normal, sino obligado que el desarrollo autonómico de sus preceptos no sea el mismo en todas las comunidades.

b) Las comunidades autónomas han optado por no proceder al desarrollo autonómico de los preceptos de la LRSAL o bien por hacerlo de manera muy restringida. Y además, como hemos advertido, habitualmente movidas por la intención de obstaculizar la aplicación de la ley estatal. Esto se traduce, más allá de las medidas concretas adoptadas, tanto en la densidad de la regulación autonómica como en su alcance. Desde esta última perspectiva, en efecto, lo más común es que tenga como objeto únicamente aquellas cuestiones inaplazables que mayores disfunciones eran susceptibles de generar en la práctica local: la situación de las competencias locales atribuidas por la legislación autonómica antes de la entrada en vigor de la LRSAL, el régimen de las competencias distintas de las propias y de las atribuidas por delegación del nuevo art. 7.4 LBRL, la necesaria adaptación de los convenios de colaboración y, por último, el trato a dar a las competencias locales en materia de educación, sanidad y servicios sociales.

c) Desde un punto de vista formal, el desarrollo autonómico de la LRSAL se caracteriza por la diversidad instrumental empleada: leyes, decretos-leyes, reglamentos, circulares y notas. En ellas, no siempre queda claro cuando estamos ante un auténtico desarrollo normativo de las bases estatales, en ejercicio de la competencia legislativa compartida que corresponde a la comunidad, y cuando ante una mera disposición aclaratoria o interpretativa de una ley estatal particularmente enrevesada y confusa. Es más, no siempre está clara la naturaleza normativa de la disposición en cuestión.

De lo que no hay duda, en cambio, es acerca de la preferencia autonómica por el empleo de normas con rango legal (ley y decreto-ley). Teniendo en cuenta que la mayoría de las cuestiones reguladas no son materias reservadas a la ley, se han querido buscar dos razones complementarias que expliquen este hecho ${ }^{25}$. Por un lado, y ante la incertidumbre generada con la entrada en vigor de la LRSAL, la voluntad de ofrecer a los operadores jurídicos locales una interpretación de ella a la que pudieran acogerse y que les proporcionase el mayor nivel posible de seguridad jurídica. $Y$, en segundo lugar, el deseo del normador autonómico de imponer a sus gobiernos locales una interpretación homogénea -que, además, fuese la suya propia- de la regulación contenida en la LRSAL.

25 Seguimos aquí a Marcos Almeida Cerrada, en su ponencia ya citada "El papel de las comunidades autónomas y la reinterpretación de la LRSAL". 
Esto último tiene importancia en tanto que las propias entidades locales, especialmente las de mayor relevancia, habían comenzado ya a aprobar sus propias guías interpretativas de la ley estatal.

Llama también la atención el alto número de decretos-leyes autonómicos dictados para adoptar las medidas necesarias para hacer posible la aplicación de la LRSAL en los correspondientes territorios. Una tendencia que debe enmarcarse en la más general -y abusiva-propiciada por la crisis económica y la aprobación de medidas para hacerle frente. Puede ponerse en duda, en estos casos, la concurrencia del presupuesto habilitante de la extraordinaria y urgente necesidad. En especial si tenemos presente que algunas comunidades han podido aprobar leyes tras seguir el correspondiente procedimiento parlamentario. Esta cuestión ha sido objeto de análisis en el Dictamen 16/2014, de 11 de julio, del Consejo de Garantías Estatutarias de Cataluña, en relación con el Decreto-ley catalán 3/2014 ya citado. Pues bien, en breve, el órgano consultivo consideró que solamente concurría el presupuesto habilitante en la materia relativa a la adaptación de convenios y no en el resto de contenidos de la norma. Lo que provocó, tras su no convalidación parlamentaria y su consiguiente derogación, la aprobación de un nuevo Decreto-ley 4/2014 con un objeto limitado a ese aspecto. Debe advertirse, no obstante, que el examen realizado en el Dictamen tiene también en cuenta que la regulación de los gobiernos locales catalanes, con los límites allí fijados, es materia reservada a un tipo reforzado de ley autonómica (ley de desarrollo básico del estatuto), que se encuentra, por imperativo estatutario, excluida de la posibilidad de regulación mediante decreto-ley autonómico. 
